\title{
Little Silent Spiders: Social Workers in Building New Relationships at the Time of COVID-19*,\#
}

\author{
Maurizio Esposito', Elena Addessi ${ }^{2}$ \\ ${ }^{1}$ Professor of Sociology Coordinator of Degree in Social Work, University of Cassino and Southern Lazio, Cassino, Italy \\ ${ }^{2}$ Specialist Social Worker at LT/5 Social District, Gaeta, Italy \\ Email:m.esposito@unicas.it, addessi.elena@gmail.com
}

How to cite this paper: Esposito, M., \& Addessi, E. (2021). Little Silent Spiders: Social Workers in Building New Relationships at the Time of COVID-19. Sociology Mind, 11, 52-63.

https://doi.org/10.4236/sm.2021.112005

Received: March 16, 2021

Accepted: April 16, 2021

Published: April 19, 2021

Copyright (c) 2021 by author(s) and Scientific Research Publishing Inc. This work is licensed under the Creative Commons Attribution International License (CC BY 4.0).

http://creativecommons.org/licenses/by/4.0/

(c) (i) Open Access

\begin{abstract}
Italy was reached by the pandemic 21 February 2020. Right away, Social Services launched initiatives to support and respond to the needs of vulnerable people, strengthening their professional experiences and changing, in a flexible manner, their ways of intervening. Social workers have woven the network, which now allows ensuring people the continuity of emergency interventions. By reorganizing their services, they have started innovative ways of being closer to people, to families and local communities, re-creating and strengthening relationships and social networks. In networking, social workers have a connecting role in creating links and synergies between various formal and informal resources in order to promote the well-being of the individual. The modus operandi of social workers is constantly evolving, as they are becoming promoters of the process of change and creators of new best practices that shape, with new professional awareness, the new social and historical context marked by the COVID-19 pandemic.
\end{abstract}

\section{Keywords}

COVID-19, Social Services, Social Relations, Networking

\section{Introduction}

In December 2019, a person in a city in central China was struck by abnormal pneumonia. It seemed an isolated phenomenon but in a very short time, it became a SARS-CoV-2 epidemic. In January 2020, the contagion reached Europe. The epidemic COVID-19 transformed quickly into a pandemic and for the first time in this century, there was a phenomenon that affected the entire world ${ }^{*}$ Aurora Aprile has translated the article and the excerpts of non-English references.

\#The article is the result of shared considerations and intense discussions between the authors. Maurizio Esposito materially wrote sections 1, 4 and 5; Elena Addessi wrote sections 2 and 3. 
population. In Italy, January 31, 2020 a state of emergency was declared, a tool that allowed the Government to use quick procedures to enact and apply the necessary measures to manage and contain the event.

The words "pandemic" and "emergency" appear in the daily lexicon of the entire world population. The pandemic is one of the phenomena that have significant health and social consequences because it causes a disruption of daily life and of collective identity generating a fracture in the balance of each person.

One of the first sociologists that linked the importance of events generated by a phenomenon to social changes was S.H. Prince in 1920 in his book Catastrophe and Social Change. Events generated by the pandemic phenomenon become the social product in terms of fragility of a society at the happening of an event. The pandemic has created a discontinuity, a fracture in the social context and in the lives of people in reference to the conditions of a society undergoing the sudden phenomenon.

The condition of vulnerability, according to Marcel Mauss (1923), French anthropologist and sociologist, is not only a state of fragility but also the reason itself of relationships and social bonds; it is an opportunity that leads a person to overcome their limits. Vulnerability provides a multi-dimensional interpretation of the phenomenon of inequality and the possibility to better understand the difficult conditions experienced by people who see some of their reference points crumble, those on which they use to found their decisions for their lives. Vulnerability exceeds risk: the difference, as Ulrich Beck (1992), German sociologist, would explain, is in the transition from the possibility to predict the fragilities (the risk) to that of their unpredictability (the vulnerability) (see Casavecchia, 2014). According to Robert Castel, that difference is in the transition from a state of relative stability to one of ordinary insecurity; in fact, "the feeling of insecurity is not entirely proportional to the real dangers that threaten a population. It is rather the effect of a difference between a socially constructed expectancy built up by protections and the real abilities, of a specific society, to make them work. Insecurity, in short, is largely the downside of a society that ensures safety" (Castel, 2011: p. IX).

As to the spreading of the pandemic COVID-19, each person has become aware of his or her own vulnerability as a human being, that same vulnerability which leads us to think about the meaning of life. "The vulnerability of people, during the emergency, amplified especially during the period of Phase 1 or lockdown: this situation highlighted the critical issues that a number of local governance systems had in managing the succession of events bringing out new fragilities. During lockdown people were forced to give up momentarily the sense of self-determination of their own existence, acknowledging the fact that the situation followed a predetermined direction by its own escaping all kinds of control" (Esposito \& Addessi, 2020: p. 466).

This unpredictable event exposed people's vulnerability regarding illnesses and death. During the pandemic, everyone feels threatened by an invisible dan- 
ger that arouses fear. "The worst fear is the widespread fear, sparse, indistinct, free, undocked, and floating, without a specific destination or a clear cause; the fear that haunts us without a reason, the threat that we should fear and that is glimpsed everywhere, but never shows itself clearly. Fear is the name we give to our uncertainty, to our not knowing of the threat, or of what should be done-what we can and cannot do-in order to stop it or, if this is not in our power, at least to handle it" (Bauman, 2008: p. 4). The uncertainty generated by fear of pandemic has exposed people to a defragmentation of their social space, made up of relationships and social ties, moreover compromised by the physical distancing. The fragility indicates a state but at the same time is a condition of latency, tacit and in some cases submerged. A variable condition changes according to the evolution of the pandemic and it is different from person to person. During the lockdown, with the closure in their homes to avoid infection and the spreading of the virus, people have sacrificed their personal freedom. Each person had to reorganize with time, his or her social relationships. People are crushed in an unselected and precarious present and in an uncertain future. Recognizing a state of fragility of the individual is to act quickly with targeted network measures, enabling people to empower and react to the event in a resilient manner.

It is precisely in timely action that the professional action of social workers is placed in the emergency of the pandemic. An intervention that becomes professional action, put under pressure by the emergency, when the front office, face-to-face interview and direct contact with people are no longer allowed, due to compliance with safety regulations and physical distancing. Non-direct contact with people and physical distancing has contributed to the change in social relations, and indeed the COVID-19 pandemic has made it possible to reveal how important they are. "Without relationships the virus does not exist. It does not exist as a social fact. Human persons cannot live without relationships with other human beings; they have to deal with the virus in/with/through relationships. That is, within relationships. This means that relationships count very much, indeed they are decisive for life" (Donati \& Maspero, 2021: p. 9). If relationships are decisive for people's lives, without which one cannot live, theoretical framework of the authors is "relational sociology" (see Donati, 2013), and the main questions are the following: how has the pandemic changed the professional relationship between social workers and vulnerable people? How, through professional action, have social workers managed to weave new interweaving of relationships and mend existing ones while respecting the physical distancing imposed by the pandemic emergency?

\section{Social Services and Social Relations}

The role of a social worker is to "promote, develop and support integrated social policies aimed at improving the social well-being and quality of the life of the members of the community, particularly regarding those who are most exposed 
to fragile situations, vulnerability or at risk of exclusion, taking also into account the level of responsibility that the social worker has, considering the effects his activity can have" (CNOAS, 2020: p. 17).

A social worker organizes his professional action, consistent with the provisions of his organization, having direct responsibility even in case of emergencies. "The social worker provides the authorities with his/her competence through programs and interventions directed to overcome a state of crisis in the event of disasters or maxi-emergencies" (CNOAS, 2020: p. 17). From the very beginning, the evolution of the pandemic of COVID-19 phenomenon led us to think that the emergency would not only regard health but was also social and economic. In fact, the National Council of the Order of Social Workers specified that "the emergency situation is completely new and unpredictable and every Social Worker finds himself in a double role: potential victim and rescuer at the same time.

The current outbreak of COVID-19, however, presents an unprecedented scenario as well as complex in terms of the interventions of Social Service that so far no institution, neither public nor of the Third Sector, has ever faced or perhaps ever contemplated. All urgent activities and those that cannot be postponed in the field of essential services should be guaranteed to the people. The function of the social worker in order to support individuals and families, whom, because of the emergency are in situations of vulnerability, is essential. The role of the social worker in every area, regardless of the type of contract or organization (public, private or third sector), and in any role (including managerial and coordination), is crucial in this phase of crisis and, therefore, the necessary monitoring interventions (even remotely) cannot be interrupted" (Circular of March 16, 2020 of the National Council of the Order of Social Workers, p.1).

The Social Services System, "with its central role, must continue to guarantee and strengthen the services that can contribute to the better application of government directives, to maintain maximum social cohesion. It is a role that the Social Services System has to play towards all the members of our society, with special attention to those who are in a position of fragility, also in relation to the need to guarantee basic levels of social benefits referred to art. 22, paragraph two, of law no. 328 of 2000" (Circular Letter of 27 March 2020 of the Ministry of Labor and Social Policies, p.2).

All over the country, the role of social workers has aimed at maintaining social cohesion, a goal supported by the knowledge of local resources that have focused professional action towards the enhancement of professional services. The professional actions have allowed the increase in pro-activity of the listening services, aiming at actions of empowerment and advocacy. The Social Services, to face the social emergency, have launched initiatives in their local welfare to support and respond to the needs of vulnerable people, they have innovated and strengthened professional experiences already present by changing flexibly their 
ways of intervention and reorganizing their services through the deployment of new forms of closeness to the people, families and local communities. The Social Services have never stopped; they have never stopped being there: like little silent spiders, they have slowly woven the network that today allows people to ensure the continuity of emergency interventions.

One of the tasks of the social worker in emergencies is to support the system of communication and information between the citizen and the institutions. The accurate knowledge of the social and economic territory and of the entities of the third sector allows the social worker to establish connections with the population, in order to create a network to be activated effectively, even in an emergency.

The pandemic has brought the world to go through a period of suspension, a surreal dimension felt in lockdown, when the population is asked to stay at home to prevent the viral infection and to avoid the spread of the pandemic. The same emergency, in fact, can have many different phases that characterize the phenomenon and can offer a reading of kaleidoscopic type, namely multi-faceted and complex, inside of which several macro meanings become apparent as for example the emergency considered both as a psychological and as a social issue" (Isidori \& Vaccarelli, 2013: p. 73).

The social worker promotes relations between people living in the same territory or sharing the same difficulties, carrying out joint measures for their own welfare, supports, and he/she promotes networks of community and the spontaneous activation in local communities. We refer to Community Work whenever social workers are engaged in work aimed at organizing common actions, aimed at achieving not only personal but also structural objectives. In the Community Work, the social worker does not work with the single individual but with the community, seeking to promote and enhance the resources that are present in that territory and seeks to promote the knowledge of the area and the community regarding a specific problem. Social Services encourage the empowerment of the individual and the community, trying to improve through collective action the quality of life and creating connections between organizations. The Community work involves the culture of solidarity and its principles, expressed in the Italian Constitution, protecting the essential condition for the practical implementation of social equality.

Solidarity is a basic factor for mobilizing the motivations and resources of the population; in fact, the work done "in" and "with" the local community develops networks of solidarity by building social networks that act as social support.

The culture of solidarity, the commitment of people and Social Services have supported most parts of the fragile population and of the social system during the pandemic. The principle of social ethics that identifies solidarity implies the responsibility towards the vulnerable people who live in need, because every person is a potential carrier of resources and social capital. Social solidarity is a fundamental value of our society that motivates and leads to legitimate inter- 
personal relationships as those built daily by the individuals that compose it. It is built based on individual citizens, giving value to collective actions through new forms of sharing. The principle of solidarity is combined to the autonomy and the right of the person leading to the consciousness of interdependence between human beings. In social solidarity there is an individual responsibility to follow the behaviors targeted to a collective action, aimed at supporting vulnerable people.

According to the sociologist Émile Durkheim (1893), the relationship between individual and community is the premise of any social formation and solidarity. Regarding this assumption, he identifies two forms of solidarity, the mechanical one, the same one for all members of primitive societies, and the organic one, where each individual performs his own function considered indispensable. "The solidarity of modern societies is organic both in the sense that the individual, member of the society, is the cell of a bigger organism that includes and validates it, whether that individual is organic in this type of society, which is synchronic and symbiotic to it, outside it would have no sense or life. Solidarity is therefore a general functional value that crosses a society, and the individual that inhabits society, as the interpreter of it, will have a take it up as the scene of his transcendence" (Toscano, 1996: p. 28).

So, the transcendence of the individual who inhabits society is culturally oriented towards solidarity, social cohesion, and enhances his role of active citizenship and civic engagement heard as part of his duty. Active citizenship makes it possible to promote processes capable of favoring the creation of responsible citizenship, guaranteeing protection for vulnerable people. Solidarity during emergency is seen as a strength and as a tool of intensification of social relations. The feeling of humanity, located at the base of social solidarity, drives a person to show concern for the needs of vulnerable people living difficulties related to the pandemic COVID-19. During the emergency, in fact, people are continuously supported; but once it finishes, the same people will have to find the personal resources to carry on keeping in connection with the community, acting as key players to exit the condition of need. They could support the community, which had supported then during the emergency. The social worker builds the act of proximity creating a circular network of relations between people and the community, a network of mutual and non-linear exchange, aimed to re-build the citizen bond. In this sense, social fragility becomes social responsibility.

\section{The New Professional Tools}

Information technologies, in the COVID-19 pandemic, are indispensable and effective tools for staying in contact with the outside world. "The world (world wide web) has been surrounded by a telematics network made up of points (personal computers) and lines (telephone or fiber optic lines). Each individual computer can send any message and receive any message" (Folgheraiter, 2011: p.310). During the period of national lockdown people, albeit separated by 
physical distance, people were able to be digitally nearby. Social services had to handle a new situation, but digital tools reorganized services and professional activities, and each service was re-arranged according to their competences and the organization they belonged to.

This new service management allowed the professional services to ensure telephone conversations or video calls by devices such as the telephone and the computer, with which they managed the coordination of volunteers and the social secretariat. The social secretariat assumed a central role in enabling individuals and communities to have updated information about the environmental resources and the modalities of access to services.

The introduction of video calls has led to new form of professional communication that has transformed significantly the distance in closer relationships. Communication has been filled with not only words, content and voice but also gestures. Video calls have enriched dialogues with facial expressions typical of talking in presence. Communication takes place in real time and, in addition to nonverbal contents, conveys emotions and states of mind, merging again with the verbal one. Even the access to Social Services, during the lockdown, took place by telephone or electronically; for all the other situations monitoring telephone conversations were carried out with the goal to support individuals in situations of fragility, recognizing any criticality and activating if necessary the socio-health resources. In some cases, social isolation aggravated the discomfort, already existent, of many people taken into care by social services. The Social Services have never closed and their presence has been essential, they have never stopped being close to the population. The support of digital tools has allowed them to maintain solid relations and the creation of a virtual network of services and activities. The emergency gave the opportunity to try out the services, implemented remotely, on the field, services that can also be used in the future, thereby improving some aspects of the process of help in back-office and networking. In Social Services during the pandemic, as it was not possible to have Vis à Vis contact with people in the course of the talks, the active listening and the use of the voice play an important role in the management of long-distance relationships. The active listening is what makes communication possible because it involves a range of skills, which are supposed to create empathy with the person who is talking to us. In fact, it requires not only a deep understanding of what the other person is saying, but also the redesign and reformulation he expresses in order to feel his emotions and providing proximity, contributing fully to each moment of the communication. "The symbolic significance of the words involves in the social worker the search for a certain sensibility into listening to the same that are specific of that person, its metaphors, its idioms, adjectives that he mostly repeats, that particular mode that we define personal style, to shape one's existence and one's problems. People need their own words, as to say their mental representations, in order to understand what is happening to them and to support difficult changes" (Allegri, Palmieri, \& Zucca, 2006: p.62). The voice, on the other hand, is a communication tool, and expresses emotions through 
many prosodic nuances regardless of the meaning of the words. It gives shape to what one is thinking and shows how one relates to the external environment. The voice emits sounds that form a "fabric of words that are exchanged by the actors, words that must be considered in their double dimension of meaning (what messages do they convey?) and of signifier (with what forms do we give a name to experiences?)" (Ibidem). The social interview is made up of words: words that are said and words that are heard. Through these new modes of use of professional tools, an awareness has grown that the professional activities could be performed, in some cases, even from home. Social Services have experienced therefore new forms of "remote presence" that supported and strengthened the link with fragile subjects. These long-distance relationships have allowed and still allow avoiding the risk of contagion.

\section{Social Relations and Networking. Beyond the Social Distancing}

Even during the Emergency, the professionalism of a social worker is characterized by his attitude in knowing, knowing how to do and knowing how to be: specifically, Social Services have shown their skills (knowing) that have allowed them to work through their professional methods and techniques (Knowing-how), supporting relationships with the population in the fragility generated by the pandemic (knowing how to be). In knowing how to be the social worker, while being physically distant from the people, he/she remains connected through alternative forms of closeness, because physical distance is not necessarily social distance.

In this regard, in article "Physical distance, social contact: OMS clarifies why the term used is physical distancing and not social distancing" (published on the website www.sossanita.org/archives/10399), it is reported as follows: "The World Health Organization (OMS) claims that we should overcome, in this time of pandemic, the concept of social distancing in favor of the concept of physical distancing. Especially because the expression "social distancing" could create misunderstandings. What must be maintained, to counter COVID-19, is physical distancing. The virus can in fact spread through respiratory droplets, small amounts of liquid that could come out when someone with the disease coughs or sneezes. Limiting contact with others and maintaining physical distance of at least one meter reduces the chances of contracting the virus and transmitting it to someone else. The strengthening of social bonds should be enhanced, promoting also sociability as a positive concept able to maintain and increase mental and physical wellbeing. Social contact is vital for mental health and its lack can generate anxiety and feelings of loneliness depriving people of substances given by physical contact, such as endorphins and serotonin, that help keep stress and fear under control".

In an interview with the Washington Post, Daniel Aldrich, professor of political science at Northeastern University in Boston, said that efforts to slow the spread of the coronavirus should encourage the strengthening of ties and social 
relations while maintaining physical distance. According to him, the maintenance of social connections during disasters is crucial: the stronger social bonds are in a community, the better it will be able to overcome the difficulties (see Penassi, 2020). With physical distance, you can also have social closeness without having direct contact because presence can even be at a distance, as this is possible through networking.

During the emergency, it was so important that Social Services maintain social cohesion through networking and community work. Networking and community work is made up of people, relationships, social networks and professionals. "The concept of network, both in the singular and in the plural, is used to define connection systems, communication networks, strategies implemented by individuals, and forms social relations. The anthropologist Barnes coined the term social network in 1954 to describe a phenomenon, detected in existing interactions in a small parish of a Norwegian island, characterized by a type of relationship that did not fit nor in the field of labor relations, and neither in those of the neighborhood linked to the territorial organization. Through the term 'network' Barnes wanted to mean that set of ties specific to each inhabitant of the island that linked relatives, friends, neighbors and that crossed the other two fields of relationships, being intermediate between them" (Sanicola, 2005: p. 304).

Furthermore, "the classic definition of network by the anthropologist Barnes tells us that a network is a set of points connected by lines. The points must be at least three and they are all the same. Each point is equal to the other both on a structural and functional level: all serve to guarantee the connection between the lines that unite them to each other. Points are hubs for resources (information/goods/services of various kinds), production/distribution centers/sorting or mere transit to other joints, so that the lines that connect them can be crossed and connected by complex patterns. In this meaning, the network appears to us as an abstract entity: points and lines can be anything, not necessarily people" (Folgheraiter, 2011: p. 310).

Even the founder of relational sociology in Italy underlined this concept, stating that "the concept of network does not only intend that individuals exist in a context of relationships, that they have referential ties to each other but that there is a relationship between these bonds, meaning that what happens between two nodes of the network influences the relationship between the other nodes, both those more adjacent (which have direct relationships) and those more distant (that have indirect relationships). The network is not a collection of individuals that are in contact with each other, but is the whole situation of their relationship. From today's modern social sciences point of view, that social relationship connects social subjects as it creates a bond between them, that is, since it expresses their reciprocal action. Stay (be) in relation can have a static and dynamic meaning, can mean that you are in a given context or in an interaction that generates new forms. The classifications of the forms and types of social relations are innumerable, practically infinite, since social relations, potential and 
virtual, are uncountable both in theory and practice" (Donati, 2013: pp. 90-93).

Relationships are actually the trademark of networks, social ties that change during the course of their existence form them, and they are dynamic systems that have a beginning, a duration and an end. Each social bond requires its own reciprocity, time and dedication. The nature of social bonds demonstrates how people can be part of a concrete social fabric that leads them to live together in society. From social ties comes the human need not to isolate oneself, and to be in contact with others.

"Relationships are decisive for life. Health comes only with good relationships. The category of the relationship challenges us from the ground up. The novelty brought by the pandemic is therefore this: the revelation that social relations are a vital element of our life. Neither more nor less than the air is vital for us. And like air, relationships are also invisible" (Donati \& Maspero, 2021: p. 9). So, the invisibility of relationships and the solidity of the social bonds generated by the arrival of the pandemic have allowed the construction of networks that, as a form of social relations, are made up of three dimensions: "structure (ties, knots, affective and geographical proximity/distance in ties); functions (social support); dynamic, that is established as a series of movements within the networks. They confer some aspects to the networks, such as flexibility, transparency, strength, reciprocity, trans-nationality, circularity and reciprocity of exchanges, mobility, simultaneity and duplicity of effects" (Sanicola, 2005: p. 305).

With the advent of pandemic COVID-19, social networks connect to the existing communications networks, combining through technology functional and relational elements that lead to a plurality of organizational structuring. Online social networks have grown by delivering software and platforms that allow interaction among people, allowing them to exchange not only text files but also audio and videos. Technological innovation has intervened on social networks and allowed to attach material networks already existent, expand them, create new ones, making them evolve and transform. Above all, it has given visibility to social networks, making them more flexible and has vacated them from space and time constraints. The connections of the online social networks have shown the existence of relationships beyond physical contact and marked a turning point that allows maintaining regular contact with one's social ties. Social networks are an integral part of the social system and have been the starting point for making connections aimed at territorial and community interventions.

\section{Conclusion}

In Italy, the present time has reopened the debate on the value of social policies. In the work of Social Services, repair work for the emergency has been prolonged in time and strongly exceeds that preventive one. The consequence is that the services have often lost their function of promoting health and well-being, focusing on interventions to contain the phenomenon from a social point of 
view to limit the damage. Among the preventive measures to be addressed in the emergency, there is that to prepare the organization of ones services in a different way, even according to experiences. From the experience of the pandemic, it emerged how important it is for Social Services to know the territory and be immerged in the environmental context, in order to effectively build a mapping of the services, organizations and resources present. Community work stands today as a bulwark that aims to take care and consider all social vulnerabilities and fragilities, especially in times like the present, where the anomic, fragmented disorientation is the lonely new sense of common life. A disorientation that has been well described by Bauman (2008), who uses the term Unsicherheit to describe it, that is the complex of experiences defined by the words uncertainty, insecurity (existential insecurity) and unsafety (lack of protection for one's own person, precariousness). Therefore, people that feel insecure, who are wary of what the future might hold for them and that fear for their personal safety, seem paralyzed by the individual need to the point of not being able to imagine different ways to collectively address their problems.

Through network building, the social worker can change the state of things; his/her role serves as a node inside social networks and becomes what keeps the whole network going. With his professionalism, he creates connecting bridges producing links between the resources of the territory.

Knowledge of the territory implies quick responses to the requests of the people who arrive at the service and a sudden reorganization of resources. The territory, thus, ceases to represent only a geographical expression, and becomes a place where people live human relationships in a dynamic system; a privileged place, because it is a crossroads of relationships and, ultimately, a network of networks. "The experience of the pandemic has also highlighted the importance of community-based and voluntary support networks in neighborhoods and communities of interest and identity in all parts of the world. The role of social workers and community development workers in facilitating these networks has been crucial" (Banks et al, 2020: p. 579).

Therefore, networking can be seen as a kind of lattice, in which the interweaving and union of the different resources help to cope with the emergency. Networking in Social Services consists of building links and synergies between various formal and informal resources in order to create social partnerships. The goal to achieve is to bring back the people's well-being and that of the collectivity, favoring the natural balance of social networks. Networking, in the emergency of the pandemic, has been structured as a social action project motivated by values such as solidarity and equality and has created complex territorial interventions with the aim to support the individual and intervene where a situation of need arises. The emergency is paradoxically the opportunity to test the remote and online facilities, the network as a social action project, and new strategies that may be used in the future, in a constructive vision of "policy window" (Kingdon, 1984). 


\section{Conflicts of Interest}

The authors declare no conflicts of interest regarding the publication of this paper.

\section{References}

Allegri, E., Palmieri, P., \& Zucca, F. (2006). Il colloquio nel servizio sociale. Rome: Carrocci Faber.

Banks, S. et al. (2020). Practicing Ethically during COVID-19: Social Work Challenges and Responses. International Social Work, 63, 569-583. https://doi.org/10.1177/0020872820949614

Bauman, Z. (2008). Paura liquida. Bari: Editori Laterza [orig. 2006].

Beck, U. (1992). Risk Society. London: Sage.

Casavecchia, A. (2014). Vulnerabilità sociale. https://www.benecomune.net/rivista/rubriche/parole/vulnerabilita-sociale

Castel, R. (2011). L'insicurezza sociale, che significa essere protett? Torino: Piccola Biblioteca Einaudi [orig. 2003].

CNOAS (2020). Code of Ethics of Social Worker. Rome.

Donati, P. (2013). Sociologia della relazione. Bologna: Il Mulino.

Donati, P., \& Maspero, G. (2021). Dopo la pandemia, rigenerare la società con le relazioni. Rome: Città Nuova Editrice.

Esposito, M., \& Addessi, E. (2020). Il servizio sociale in Italia al tempo della pandemia. Per una presa in carico globale delle fragilità sociali. Fascicolo speciale Democrazia e diritti sociali. https://www.democraziaedirittisociali.it/wp-content/uploads/2021/01/Covid19.pdf

Folgheraiter, F. (2011). Fondamenti di metodologia relazionale. Trento: Erickson.

Isidori, M. V., \& Vaccarelli, A. (2013). Pedagogia dell'emergenza, didattica nell'emergenza. Milano: Franco Angeli.

Kingdon, J. W. (1984). Agendas, Alternatives and Public Policies. Boston, MA: Little, Brown and Company.

Mauss, M. (1923). Essai sur le don forme et raison de l'échange dans les sociétés archaïques. L'Année sociologique, 1, 30-186.

Penassi, M. (2020). Distanza Fisica, Contatto Sociale. Dors. http://www.sossanita.org/archives/10399

Sanicola, L. (2005). Dizionario di Servizio Sociale-Intervento di rete. Rome: Carrocci Faber.

Toscano, M. A. (1996). Introduzione al servizio sociale. Bari: Editori Laterza. 